\title{
Two-dimensional hygrothermal modelling of masonry walls accounting for imperfections at the masonry joint.
}

\author{
Michael Gutland ${ }^{1, *}$, Scott Bucking ${ }^{1}$, Mario Santana Quintero ${ }^{1}$ \\ ${ }^{1}$ Carleton University, Department of Civil and Environmental Engineering, 1125 Colonel By Drive, Ottawa, Canada.
}

\begin{abstract}
Hygrothermal models are important tool for assessing the risk of moisture-related decay mechanisms such as freeze-thaw in historic masonry structures. There are several sources of uncertainty when modelling masonry, related to material properties, boundary conditions, quality of construction and twodimensional interactions between mortar and unit. This paper examines one potential source of uncertainty; the imperfect nature of mortar joints. This interface may feature hairline cracks or imperfect bonds which can be modelled as a fracture. This will alter the rate of liquid transport into and out of the wall and impede the liquid transport between mortar and masonry unit. This means that the "effective" liquid transport of the wall system will be different then if measured properties of the bulk material were modelled. A detailed methodology for modelling the interface as a fracture is presented including material property definition. Two-dimensional DELPHIN models of masonry walls were created to simulate this interaction with varying levels of fracture widths (apertures). A series of hygrothermal simulations were performed to demonstrate change in moisture profile from the baseline condition. A significant increase in moisture absorption was found. This was dependent on aperture size, material and the relative size of the masonry modelled.
\end{abstract}

\section{Introduction}

Hygrothermal models are important tool for assessing durability of masonry envelopes. Damage mechanisms caused by excessive moisture include freeze-thaw action, leaching of mortar and corrosion of embedded metallic elements. There are several sources of uncertainty when modelling moisture transport in masonry related to the material properties (eg. absorption curves), boundary conditions (eg, amount of wind-driven rain), construction quality (eg, open joints, imperfect contact) and twodimensional interactions between the mortar and unit. These uncertainties can make calibration of hygrothermal models difficult and reduces our confidence in the model's conclusions.

This paper examines two sources of uncertainty; the imperfect nature of the mortar-unit interface and the twodimensional interactions caused by it. Imperfections can be in the form of physical separations between mortar and unit (from an open joint down to hairline crack) or an imperfect contact between the two. Intuitively, we would assume that there will be an increase in liquid water penetration into the wall if cracks are present. A method is outlined to model these imperfections by modelling them explicitly as a fracture. The derivations of the fracture material properties are explained and how to insert this into commercial hygrothermal modelling software is demonstrated. Different size fractures (apertures) were modelled for a brick/cement mortar and sandstone/lime mortar combination in wetting and drying to see the change in moisture content over time when compared to a baseline scenario without the fracture.

\section{Literature Review}

It is common procedure to make the following assumptions for hygrothermal modelling:

1. Materials are homogeneous. There are no localized variations in pore structure, physical properties or chemical composition.

2. Adjacent materials are in perfect contact with each other.

3. Materials are without imperfections.

For masonry walls, these assumptions are not always valid. There are several examples of modelling both fractured building materials and imperfect contact in the academic literature.

Studies have demonstrated that there is an interface resistance $\left(R_{I F}\right)$ between the mortar and unit which inhibits liquid moisture transport across the interface. This is caused by two reasons; first there is a gap between the two materials and moisture needs to travel across the gap via vapour diffusion instead of through quicker capillary

\footnotetext{
* Corresponding author: michaelgutland@cmail.carleton.ca
} 
action. The second reason is migration of fine particles toward the mortar joint during the curing stages (Brocken, 1998). The fine particles form smaller pores near the interface and this reduces liquid flow.

Laboratory testing has measured the interface resistance between $1.0 \mathrm{E} 08$ and $1.0 \mathrm{E} 12 \mathrm{~m} / \mathrm{s}$ [1]-[3]. Simulations have also demonstrated the effect that the interface resistance has on moisture absorption [4], [5]. The interface resistance does not consider liquid water absorption through the fracture.

Water absorption in fractured materials (brick and concrete) has been studied by Roels and Rouchier in 2D [6], [7] and by Li and Smyl in 3D [8], [9]. In all scenarios, the water absorption was increased through the porous media. These studies had a few procedural weaknesses in their applicability to masonry. First the fractures required detailed geometric analysis and discretization into a finite-element grid. This will require increased time, effort and computational costs and is difficult to generalize for large sections of wall or the variety of crack patterns which could be encountered. The second is that the testing and simulations were done on homogenous materials, meaning that the material was the same either side of the fracture. In a masonry interface that is not true as the material properties of the two adjacent materials may be quite different. These studies also looked primarily at water uptake and did not consider the drying phase or realistic boundary conditions for a building envelope. Considering this, a simplified model is proposed where cracks at the mortar-unit interface are explicitly modelled as fractures.

\subsection{Fractures}

Liquid water transport in fractures is similar but distinct to that of traditional capillary mechanics in porous media. This has been studied in the field of geohydrology for purposes such as natural gas extraction via fracking. Fluid flow in fractures is bounded only on two sides, whereas in capillaries it is bound in all directions. A fracture will also have fewer obstructions than the bundle of capillaries model and have less resistance to moisture flow.

The Cubic Law or Reynold's Equation is used to calculate fluid flow in fractures. This equation has its origins in the Navier-Stokes equation and is based on the assumption that the fracture be modelled as smooth parallel plates.

$$
\frac{\partial \boldsymbol{u}}{\partial t}+(\boldsymbol{u} * \nabla) \boldsymbol{u}-\frac{\mu}{\rho} \nabla^{2} \boldsymbol{u}=-\frac{\nabla P}{\rho}+F
$$

where: $\mathrm{u}=$ fluid velocity $(\mathrm{m} / \mathrm{s}), \varrho=$ density $(\mathrm{kg} / \mathrm{m} 3)$,

$\mathrm{P}=$ pressure $(\mathrm{Pa}), \mathrm{F}=$ sum of external forces per unit mass $\left(\mathrm{m} / \mathrm{s}^{2}\right)$

If external forces are neglected, and one-dimensional flow and steady-state conditions are assumed, then Equation 1 can be transformed into the Cubic Law:

$$
Q=-\frac{\nabla p w h^{3}}{12 \mu}
$$

or as a mass flow rate:

$$
\dot{m}_{l}=\frac{\rho h^{2}}{12 \mu} \nabla P_{c}
$$

where: $\mathrm{m}_{\mathrm{l}}=$ mass flow rate of liquid $(\mathrm{kg} / \mathrm{s}), \varrho=$ density $(\mathrm{kg} / \mathrm{m} 3)$, $\mathrm{h}=$ aperture $(\mathrm{m}), \nabla \mathrm{P}_{\mathrm{c}}=$ capillary pressure gradient and $\mu=$ dynamic viscosity $(\mathrm{kg} / \mathrm{m}-\mathrm{s})$

The first term of Equation 3 is the liquid conductivity of the fracture and is similar in form to the HagenPoiseuille equation liquid flow through tubes. The difference between the two is the denominator and that aperture is used instead of the capillary radius.

For the Equation 3 to work, the aperture needs to be determined. The aperture is the distance between the upper and lower boundary surfaces. One assumption for the Cubic Law is that the aperture is that the distance between the two surfaces remains constant throughout the fracture. This is not representative of fractures in masonry. Fractures are non-uniform; the aperture widens and contracts, changes direction, undergoes oscillations and follows a tortuous path as fluid travels along its length. In this scenario, the aperture is difficult to quantify, and an alternative measure is required to determine an "effective" aperture for the fracture.

Two methods are to use the average aperture height of the fracture $\left(h^{-}\right)$, or to use what is known as the hydraulic aperture $\left(h_{H}\right)$. The hydraulic aperture is the value of $\mathrm{h}$ which would make the cubic-law true for the bulk media in question [10]. A literature review on the subject provides numerous expressions to arrive at a value for $h_{H}$ [10]. Models of fractures have been developed which consider the micro-scale aberrations and tortuosity of the flow path [11], [12].

Along with the change in aperture height, there are what are known as asperities which effect the flow path.
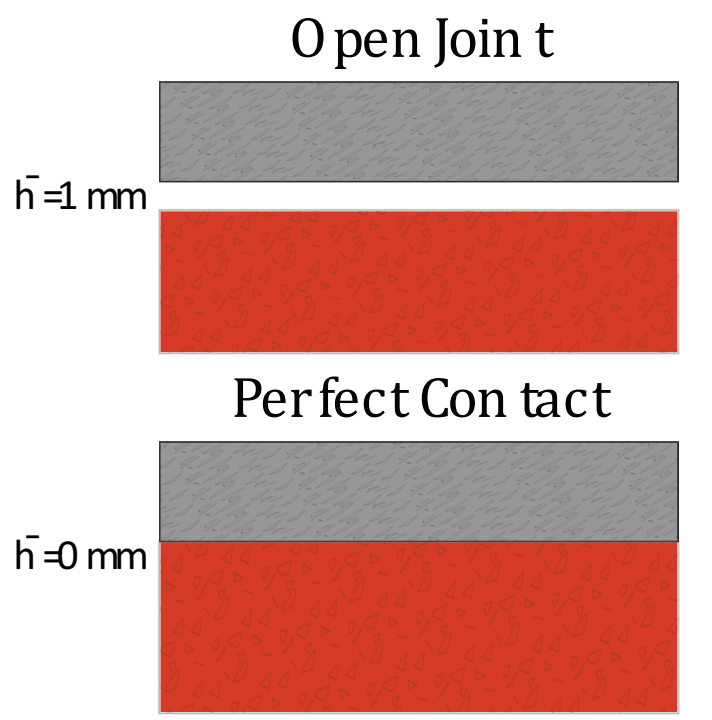

Im perf ect Cont act

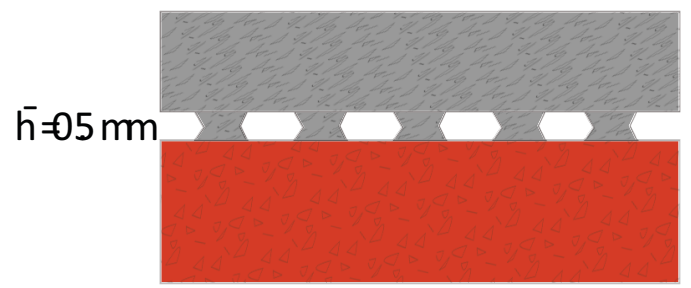

Fig. 1. Illustration of various contact conditions from an open joint to perfect contact 
Asperities are points where the upper and lower walls of the fracture are in contact with another and the aperture height effectively becomes zero. They can be visualised as vertical obstructions placed in the path of the flow and in the context of masonry, these are the points where mortar and unit bond and transmit normal forces to one another (See imperfect contact in Fig. 1). Each asperity has a radius of aspersion which is the effective radius of obstruction.

There have been many models and formulas developed to calculate the effect of asperity that depend on the size, shape and distribution of the asperities. Kirkpatrick [13] developed a theory on how asperity changes hydraulic aperture and therefore conductivity by the use of effective medium theory. From this method, the following equation predicts that:

$$
h_{H}^{3}=h_{0}^{3}(1-2 c)
$$

where $h_{H}=$ hydraulic aperture $(m), h_{0}=$ average aperture $(m)$, $\mathrm{c}=$ contact area or concentration of asperities (--)

The greater the number of asperities, the lower the effective hydraulic aperture will be and therefore reduced liquid water transport. More complex equations have been proposed and it has been found that in some cases, using the above equation with asperities considered, versus only using only the mean aperture, resulted in differences in hydraulic conductivity of more than an order of magnitude [10]. The difference between mean aperture and hydraulic aperture has been reported to be a factor of between 1.1 and 1.7 [14]. Typical apertures in subterranean rock are reported to be in the $1-100 \mu \mathrm{m}$ magnitude range [15]. Fractures in building materials range are in a similar range ([6], [7]. Anything much smaller than this and liquid transport is greatly reduced.

The advantage of using hydraulic aperture over the mean aperture is that it avoids investigating and describing the complex geometry of the fractures. It is also possible to account for any migration of fines toward the interface. The disadvantage is that it requires testing to determine its value accurately. For the rest of this paper, when the term aperture is used, we are referring to the hydraulic aperture.

\section{Methodology}

\subsection{DELPHIN Model}

Two-dimensional hygrothermal simulations were performed using DELPHIN 6.0 [16]. The model is geometrically simple, consisting only of three materials, unit, interface and mortar as shown in Fig. 2. The interface changes depending on the aperture chosen. Two sets of geometry were created; a brick/cement mortar and sandstone/lime mortar combination. The brick model was based on standard North American sizes. The sandstone model was much larger in thickness and height.

Adiabatic conditions were assumed on the top, bottom and right-hand surfaces taking advantage of symmetry. The interior and exterior boundary conditions were changed depending on whether a water uptake or drying scenario was being modelled.

Under wetting conditions, the exterior boundary conditions were set to a capillary suction pressure of 250 $\mathrm{Pa}$ to mimic a water absorption experiment (Note that lower suction pressures indicate higher wetting loads up to $0 \mathrm{~Pa}$ where the transition to hydrostatic pressure occurs). Ideally this would be set to $0 \mathrm{~Pa}$, however some numerical stability issues were encountered at very low suction pressures. However, simulations below $250 \mathrm{~Pa}$ did not provide substantially different outcomes. The initial conditions of the materials were set to $50 \% \mathrm{RH}$.

Under drying conditions, the initial conditions were set to $100 \% \mathrm{RH}$ and exposed to a boundary condition of $30 \%$ on one side only. Simulation length was set until the wetting front reached the other side. For simplification, no temperature gradient, sources/sinks or other boundary conditions such as solar radiation were considered.

Care was needed when defining the finite-element grid. Because of the sub-millimetre height of the aperture layer, individual grids in the y-direction are very small. A smooth transition between neighbouring elements is needed and a relatively large number of grids were required. An expansion ration of 1.2 was used throughout with grids clustered around the wetting boundary condition and fracture. The mass balance absolute tolerance was set to $5 * 10^{-6} \mathrm{~kg}$ at each timestep. DELPHIN's solver parameters were adjusted based on the needs of each simulations.

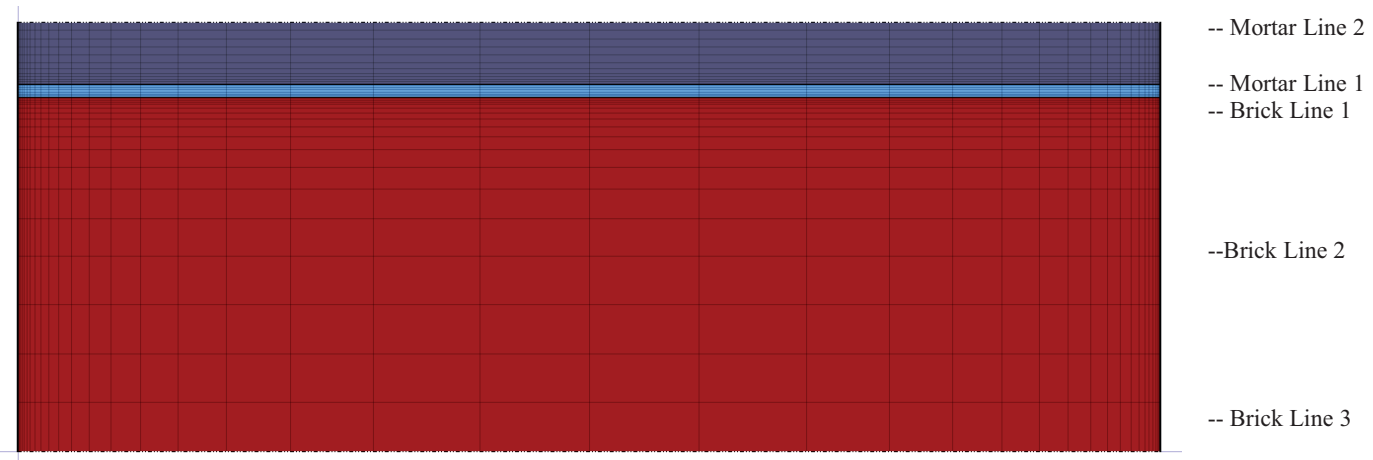

Fig. 2. DELPHIN model geometry consisting of brick (red), interface (blue) and mortar (gray). Note that the interface is not drawn to scale. 
Table 1. Bulk material properties used in DELPHIN simulations

\begin{tabular}{|c|c|c|c|c|}
\hline & Clay Brick & Sandstone & Cement Mortar & Lime Mortar \\
\hline$\theta[--]$ & 0.294 & 0.176 & 0.2296 & 0.305 \\
\hline$\lambda[\mathrm{W} / \mathrm{m}-\mathrm{K}]$ & 0.682 & 2.25 & 0.723 & 0.777 \\
\hline$\mu[--]$ & 20.2 & 25.5 & 25.6 & 11.4 \\
\hline $\mathrm{k}_{\mathrm{l}, \text { eff }}[\mathrm{s}]$ & $2.21 \mathrm{E}-09$ & $4.93 \mathrm{E}-09$ & $9.05 \mathrm{E}-12$ & $5.27 \mathrm{E}-09$ \\
\hline $\mathrm{n}[--]$ & 1.55 & 1.46 & 1.48 & 1.439 \\
\hline$\alpha[1 / \mathrm{Pa}]$ & 1.00 & 0.584 & 2.172 & 1.198 \\
\hline
\end{tabular}

\subsection{Bulk Material Property Definition}

DELPHIN allows input of custom material properties including direction-dependent properties, detailed moisture retention curves, and moisture-dependent liquid and vapour transfer coefficients.

The approach taken was to define what "typical" material properties were for the material classes listed in Table 1 instead of using a material from the library. This was done to simplify material property specification (eg. avoid multimodal pore distributions) and to avoid using materials with extreme characteristics. The hygrothermal properties for the unit and mortar were determined by the taking median values for all materials of its class in the DELPHIN library. Each database material's moisture retention function was idealized using as a single-node Van Genuchten curve where the $\mathrm{n}$ and $\alpha$ parameters were calculated via least-squares regression [17].

$$
P_{c}=\frac{1}{\alpha}\left[S_{e f f}^{-\left(\frac{n}{n-1}\right)}-1\right]^{\frac{1}{n}}
$$

where $\mathrm{P}_{\mathrm{c}}=$ capillary pressure $(\mathrm{Pa}), \mathrm{S}_{\text {eff }}=$ effective saturation $(--)$, $\mathrm{n}=$ material-specific fitting parameter $(--), \alpha=$ material-specific fitting parameter $\left(\mathrm{Pa}^{-1}\right)$.

The median values of $\mathrm{n}$ and median values of $\alpha$ were used to calculate the typical moisture retention curve for each class of material.

The approach for liquid conductivity was to use the theoretical Hagen-Poiseuille curve (Equation 5) to create the moisture-dependent curve $\left(\mathrm{k}_{1}\left(\theta_{1}\right)\right.$, integrated over the range of active capillaries [18], [19] At low degrees of saturation, only the small capillaries are filled and available for liquid transport. As the media becomes more saturated the liquid conductivity increases as the more open and freer flowing pores become active.

$$
k_{l}\left(\theta_{l}\right)=\frac{\rho}{\tau} \int_{R_{\min }}^{R} \frac{\pi r^{4}}{8 \mu_{l}} \frac{d n}{d r} d r
$$

where $\mathrm{k}_{\mathrm{l}}\left(\theta_{\mathrm{l}}\right)=$ moisture-dependent liquid conductivity (s), $\rho=$ density $\left(\mathrm{kg} / \mathrm{m}^{3}\right), \tau=$ tortuosity $(--), r=$ capillary radius $(\mathrm{m}), \mu=$ Dynamic viscosity $(\mathrm{kg} / \mathrm{m}-\mathrm{s}), \mathrm{n}=$ number of capillaries of that size.

This equation needs to be reduced by a tortuosity factor $(\tau)$, which is similar to a vapour-diffusion resistance factor $(\mu)$. Tortuosity was scaled based on the measured liquid conductivities from the DELPHIN library.

$$
\tau=\frac{k_{l}\left(\theta_{\text {cap }}\right)}{k_{l, e f f}}
$$

where $\mathrm{k}_{l}\left(\theta_{\text {cap }}\right)=$ liquid conductivity at capillary saturation from Equation 6 , and $\mathrm{k}_{1, \text { eff }}$ is the liquid conductivity obtained from physical testing in the DELPHIN library.

The vapour diffusion coefficients were calculated using the following equation:

$$
k_{v}\left(\theta_{l}\right)=\frac{\delta_{a}}{\mu}\left(1-S_{e f f}\right)\left(\frac{1}{\left(1+N_{k}\right)\left(R_{v} T\right)}\right)
$$

where $\mathrm{k}_{\mathrm{v}}\left(\theta_{\mathrm{l}}\right)=$ moisture-dependent vapour permeability $(\mathrm{s}), \delta_{\mathrm{a}}=$ Vapour diffusion coefficient for still air (s), $\mu=$ Vapour Resistance Factor (--), $\mathrm{S}_{\text {eff }}=$ Degree of Saturation (--), $\mathrm{T}=$ Temperature $(\mathrm{K}), \mathrm{R}_{\mathrm{v}}=$ Ideal gas constant for vapour $(461.5 \mathrm{~J} / \mathrm{kg}-$ $\mathrm{K}), \mathrm{N}_{\mathrm{k}}=$ Knudsen Number (--)

The fractures are assumed to be fully open and have a vapour resistance factor of 1 . It was thought that there may be some enhanced drying through the fracture, even considering its small cross-sectional area.

\subsection{Fracture Material Property Definition}

The material properties for fractures can be calculated using the equations for the bulk capillary media (Equations 5-8). The main difference is that the capillary radius ( $r$ ) is substituted for hydraulic aperture $\left(h_{H}\right)$. Another difference is that capillary materials have a pore radius distribution, whereas for our purposes, the fractures are being idealized as having a constant aperture (this is not realistic, as mentioned before real fractures have changing apertures). This will lead to problems when defining the moisture retention curve for simulation as it will essentially be a step function, instead of a smooth curve. This will lead to numerical issues in the simulation program as the transition from fully saturated to bone dry is very abrupt. To counter this, the fractures were modelled as a normally distributed curve with mean (h) and a standard deviation of $(\mathrm{h} / 2)$. This gives us an aperture distribution (similar to a pore radius distribution, and more realistic of an actual fracture) and allows us to calculate the moisture-dependent, moisture retention curve, liquid conductivity and vapour permeability required for simulation.

Fractures with apertures in the range from $0.25 \mu \mathrm{m}$ to $10 \mu \mathrm{m}$ were modelled. On the moisture retention curve, the larger apertures are located toward the left (low capillary suction) while the smaller apertures are shifted toward the right and resemble more traditional curves for porous media. This means that it requires lower capillary suction 
pressure ( $\mathrm{RH}>99.9 \%)$ to fill and activate the fracture for liquid flow. Smaller fractures can be activated at lower and more common capillary suction pressures. Larger apertures allow for higher liquid conductivity, but require low capillary suction/high $\mathrm{RH}$ conditions to become active. Otherwise the liquid conductivity is several orders of magnitude lower when dry compared to when wet. At high degrees of saturation, the liquid conductivity of the fracture is several orders of magnitude greater than the brick and mortar. It is less pronounced at drier levels. Even though the exposed area of the fracture is small it can contribute to an increase in overall moisture transport.

\section{Results and Discussion}

Results for water absorption simulation for the brick/cement mortar combination are shown in Fig. 3 and the results for the sandstone/lime mortar combination are shown in Fig. 4.

The results show that there is a significant change in moisture content depending on the aperture height compared to baseline. The extent of the increase depends
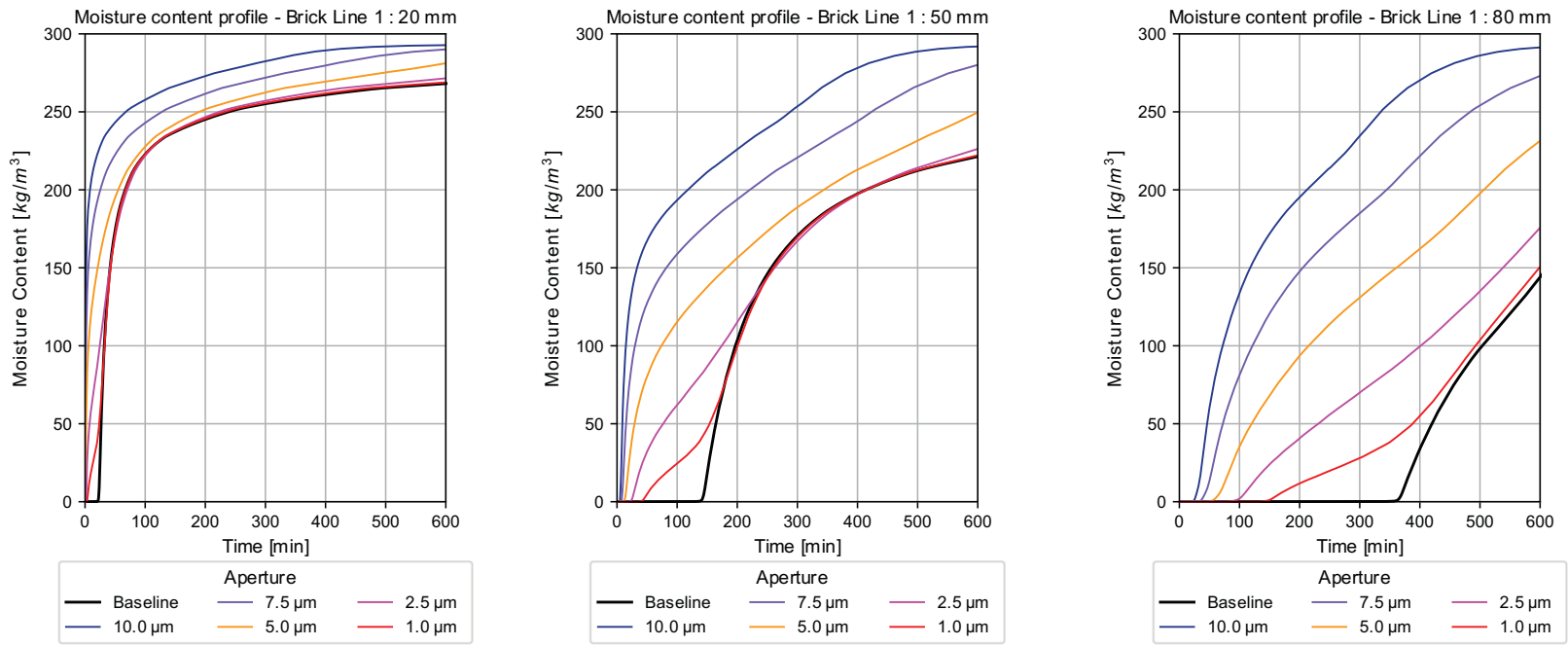

Fig. 3. Brick moisture content for the absorption experiment just below the interface at $20 \mathrm{~mm}$ (left), $50 \mathrm{~mm}$ (centre) and $80 \mathrm{~mm}$ (right)
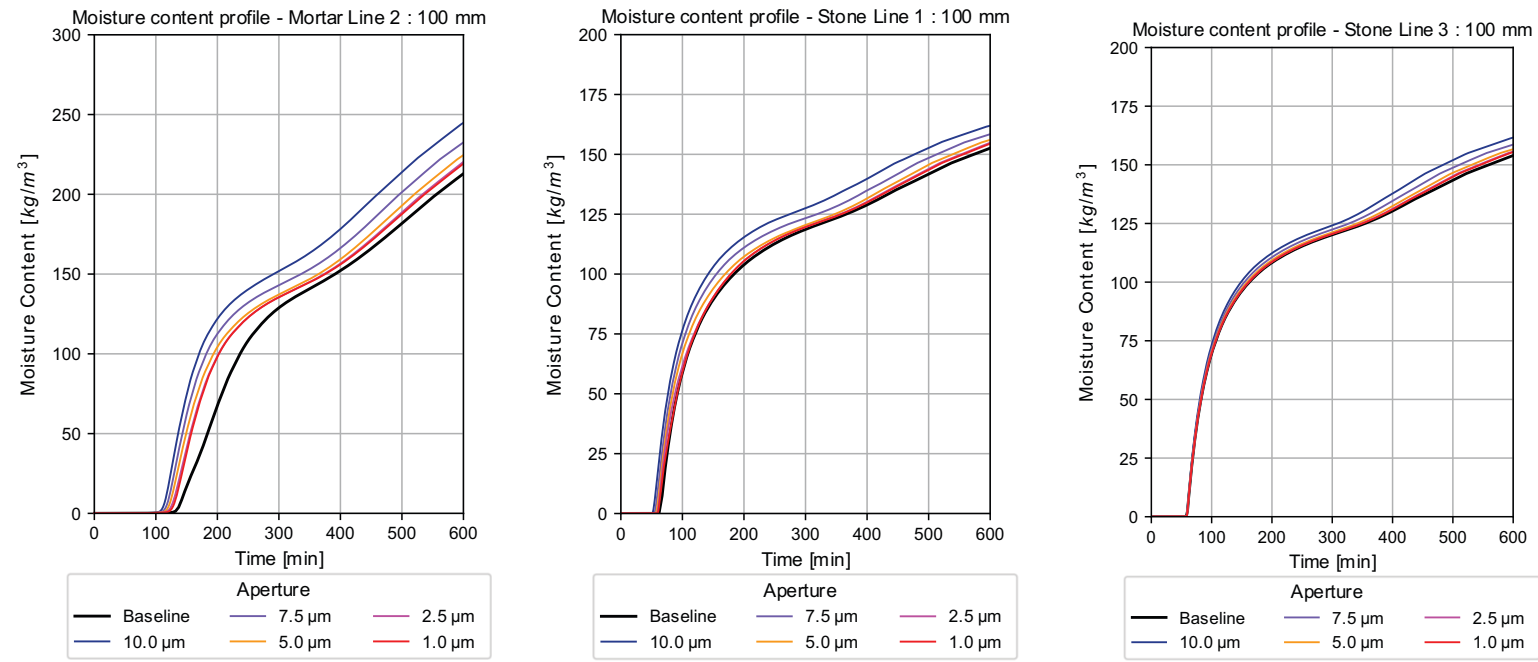

Fig. 4. Sandstone moisture content for the absorption experiment at a cross-section of $100 \mathrm{~mm}$ into the assembly. At the centre of lime mortar (left), near the fracture interface (centre), centre of sandstone unit (right). 
combination. The lime mortar has better transmission than cement mortar, so the liquid accumulating in the fracture can disperse in two directions, whereas the cement mortar inhibits transfer and forces liquid water into the brick.

The stone near the mortar (Stone Line 1) wets quicker than the other parts. As we move away from the fracture into the centre of the stone, the effect of the fracture is diminished, and the moisture absorption begins to converge to the baseline case. The impact of the fracture appears to be dependent on both the bulk material properties, the linear length/area of interfaces and the sizes of the units.

The simulations were run at $250 \mathrm{~Pa}$ of suction pressure of which is approaching hydrostatic pressure and typical of normal rain wetting. At higher suction pressures, the smaller apertures, while having a lower maximum flow rate and lower intake area, are easier to fully wet. The larger apertures despite having much higher $\mathrm{k}_{1, \text { eff }}$ and intake area are unable to fully wet and allow liquid to flow. This suggests that there may be ideal apertures for moisture transport depending on the boundary conditions applied to the fracture.

To examine if this phenomena is dependent on the boundary condition, the simulations were re-run with a new boundary conditions of $2500 \mathrm{~Pa}$ and $25000 \mathrm{~Pa}$ instead of of $250 \mathrm{~Pa}$. It was hypothesized that the maximum water content may shift to a different aperture or perhaps flatten out. This is because larger fractures would not be fully active and have reduced liquid conductivity.

The results are shown in Fig. 5. There are two important things to note. First that the moisture contents have decreased with changes to the boundary conditions. This was expected because there is less water available for transport. Second the maximum moisture content shifted toward smaller apertures as the boundary condition changed. At $25000 \mathrm{~Pa}$ boundary condition, the maximum occurs in the 2.5 -5.0 $\mu \mathrm{m}$ range. This indicates that larger apertures are more effective at transporting liquid water during heavy events and that smaller apertures are more effective during lighter rain events.

Drying drying simulations were performed over the course of one calendar year. The effect of the fracture was found to be minimal with a reduction in $\mathrm{RH}$ of less than $1 \%$ at the centre of the brick over that period. It was determined that any enhancement to vapour diffusion out through the fracture was minimal. This is explained by the relative difference in $\mathrm{k}_{\mathrm{v}}$ between the fracture and neighbouring materials not being as pronounced as the difference in $\mathrm{k}_{1}$.

The fracture model can thought of as being similar to thermal bridges for heat transfer in building envelopes. It may be difficult to consider that such a small feature could cause a significant change in flow, however its effect is comparable to a steel stud in an insulated wall assembly.

Future work will look at incorporating an anisotropic model to the fracture interface which will account for the interface resistance perpendicular to the fracture. Another round of simulations will be performed using a typical meteorological year as the boundary condition. This will determine whether the effect of the fracture is still significant under realistic weather conditions. This will introduce cyclic wetting and drying to the model and light and heavy rain conditions.

Future applications for this work are to determine 'effective' liquid absorption coefficients which can be plugged into either 2D or 1D hygrothermal models to better account for the increase in liquid transport due to imperfections at the interface. Determining what the
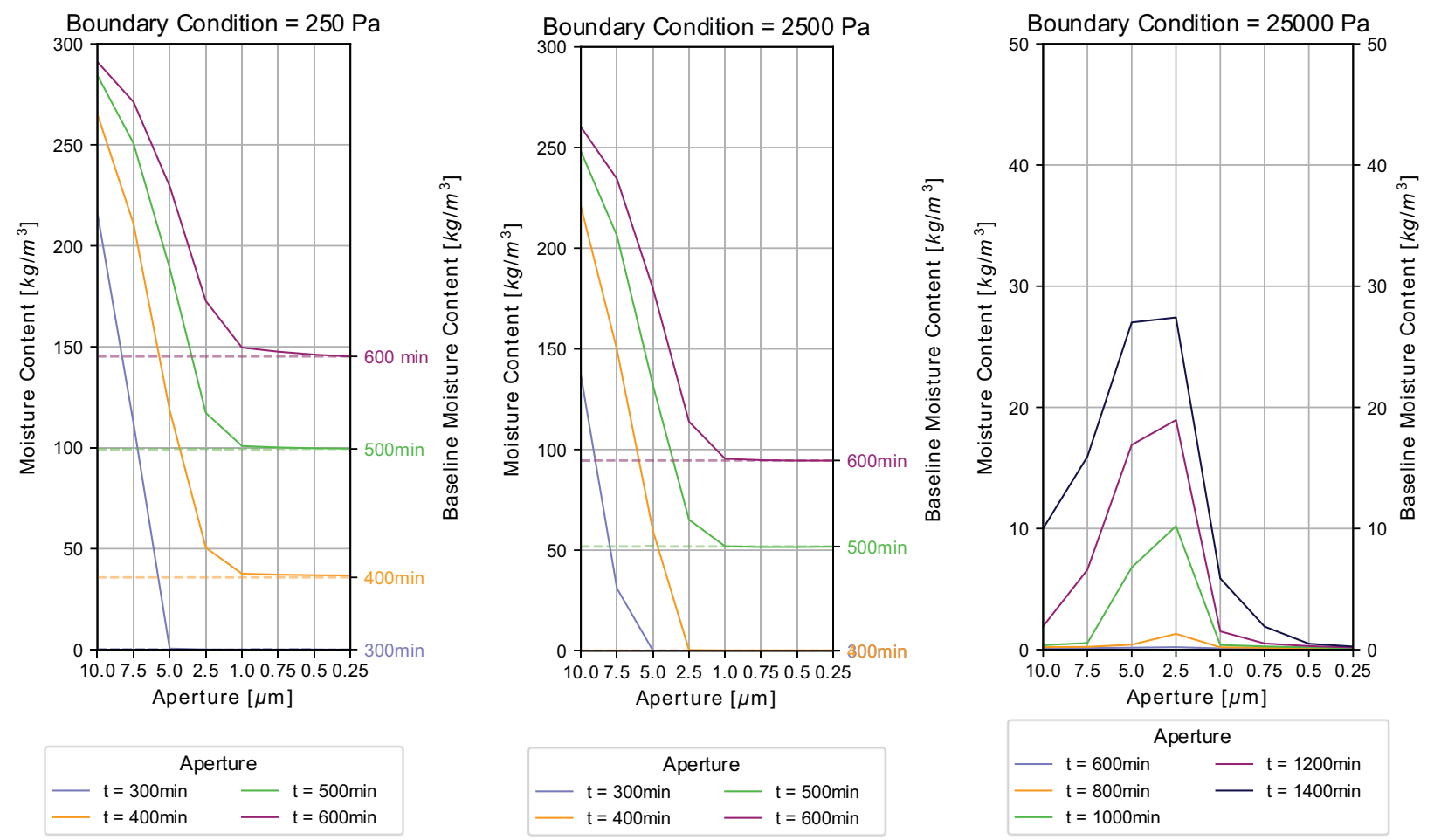

Fig. 5. Moisture content as a function of time and boundary condition (as measured at the centre of the brick).Note the different $y-$ axis scale on the figure on the right $(25000 \mathrm{~Pa})$ 
hydraulic aperture should be for an actual masonry wall is another challenge that needs to be done. This would be dependent on many things including the techniques and skill of the mason (eg. do they wet the stone), level of deterioration (good, fair, bad) and types of materials used and specification of the mortar mix.

\section{Conclusion}

The results of the DELPHIN simulations show that modelling imperfections at the masonry unit-mortar interface as fractures can affect simulation results when compared to the baseline which only used bulk material properties. Simulations were performed for both brick/cement mortar and sandstone/lime mortar combinations with an explicitly modelled fracture interface between them. Hygrothermal properties for the bulk materials and fracture were built from fundamental principles. The assemblies were simulated with boundary conditions to mimic water absorption experiments.

The simulation results showed a measurable change in moisture content compared to the baseline under high moisture loads. This was less pronounced under lesser moisture loads. The extent of the increase seems to depend on numerous other factors, including aperture size, bulk material properties, the linear length/area of interfaces and the sizes of the units.

The speed of the wetting front increases significantly. The material reaches target moisture contents quicker than without the fracture modelled.

Simulations were performed under drying conditions. The effect of the fracture in the model had minimal influence on improving drying.

\section{References}

[1] K. Calle, T. De Kock, V. Cnudde, and N. Van den Bossche, "Liquid moisture transport in combined ceramic brick and natural hydraulic lime mortar samples: Does the hygric interface resistance dominate the moisture transport?," J. Build. Phys., vol. 43 , no. 3 , pp. 208-228, Nov. 2019, doi: $10.1177 / 1744259119857762$.

[2] H. Derluyn, H. Janssen, and J. Carmeliet, "Influence of the nature of interfaces on the capillary transport in layered materials," Constr. Build. Mater., vol. 25, no. 9, pp. 3685-3693, Sep. 2011, doi: 10.1016/j.conbuildmat.2011.03.063.

[3] X. Qiu, F. Haghighat, and M. Kumaran, "Moisture Transport Across Interfaces Between Autoclaved Aerated Concrete and Mortar," J. Build. Phys., vol. 26, Jan. 2003, doi: 10.1177/109719603032804.

[4] E. Vereecken and S. Roels, "Hygric performance of a massive masonry wall: How do the mortar joints influence the moisture flux?," Constr. Build. Mater., vol. 41, pp. 697-707, Apr. 2013, doi: 10.1016/j.conbuildmat.2012.12.024.

[5] X. Zhou, G. Desmarais, P. Vontobel, J. Carmeliet, and D. Derome, "Water uptake in masonry: effect of brick/mortar interface," in 7th International
Building Physics Conference Proceedings, Syracuse, 2018, pp. 103-108.

[6] S. Roels, K. Vandersteen, and J. Carmeliet, "Measuring and simulating moisture uptake in a fractured porous medium," Adv. Water Resour., vol. 26, no. 3, pp. 237-246, Mar. 2003, doi: 10.1016/S0309-1708(02)00185-9.

[7] S. Rouchier, "Hygrothermal performance assessment of damaged building materials," Doctorate, Université de Lyon, Lyon, 2012.

[8] X. Li, S. Chen, Q. Xu, and Y. Xu, "Modeling Capillary Water Absorption in Concrete with Discrete Crack Network," J. Mater. Civ. Eng., vol. 30, no. 1, p. 04017263, Jan. 2018, doi: 10.1061/(ASCE)MT.1943-5533.0002122.

[9] D. Smyl, M. Hallaji, A. Seppänen, and M. PourGhaz, "Three dimensional electrical imaging of moisture ingress in mortar," in American Concrete Institute, ACI Special Publication, 2016, vol. 2016-January, pp. 27-48.

[10] R. W. Zimmerman and G. S. Bodvarsson, "Hydraulic Conductivity of Rock Fractures," Lawrence Berkley Laboratory, Oct. 1994.

[11] S. R. Brown, "Fluid flow through rock joints: The effect of surface roughness," J. Geophys. Res. Solid Earth, vol. 92, no. B2, pp. 1337-1347, Feb. 1987, doi: 10.1029/JB092iB02p01337.

[12] S. Ge, "A governing equation for fluid flow in rough fractures," Water Resour. Res., vol. 33, no. 1, pp. 53-61, Jan. 1997.

[13] S. Kirkpatrick, "Percolation and Conduction," Rev. Mod. Phys., vol. 45, no. 4, pp. 574-588, Oct. 1973, doi: 10.1103/RevModPhys.45.574.

[14] E. Hakami, "Aperture Distribution of Rock Fractures," Ph.D, Royal Institute of Technology, Stockholm, 1995.

[15] L. J. Pyrack-Nolte, L. R. Myer, N. G. W. Cook, and P. A. Witherspoon, "Hydraulic and mechanical properties of natural fractures in lowpermeability rock," Research Org.: Lawrence Berkeley Lab., CA (USA), 1987.

[16] Bauklimatik Dresden, DELPHIN 6.0. Dresden, 2018.

[17] Martinus. Th. van Genuchten, “A Closed-form Equation for Predicting the Hydraulic Conductivity of Unsaturated Soils1," Soil Sci. Soc. Am. J., vol. 44, no. 5, p. 892, 1980, doi: 10.2136/sssaj1980.03615995004400050002x.

[18] N. T. Burdine, "Relative Permeability Calculations From Pore Size Distribution Data," SPE-225-G, vol. 5, no. 03, pp. 71-78, Mar. 1953, doi: $10.2118 / 225-\mathrm{G}$.

[19] G. Scheffler, J. Grunewald, and P. Häupl, "Calibration of an engineering model of hygrothermal material characterisation," in Council for Research and Innovation in Building and Construction W40 Meeting, Glasgow, Scotland, 2004. 